\title{
PENERAPAN BUDAYA KERJA DAN KONTROL MANAJEMEN DALAM UPAYA MENINGKATKAN MOTIVASI KERJA
}

\author{
Anggraeni \\ Universitas Nasional, Jakarta \\ Email : anggraenifna@gmail.com
}

\begin{abstract}
ABSTRAK
Motivasi kerja merupakan faktor psikologis bagi kinerja, prestasi, dan produktivitas kerja. Artinya, semangat kerja menjadi variabel yang menentukan kualitas pelaksanaan kerja, sejauh mana pegawai memiliki keinginan tinggi dan perasaan optimis mencapai tujuan yang telah ditetapkan. Penelitian ini bertujuan mengungkapkan kemungkinan terjadinya motivasi kerja yang ditinjau dari aspek budaya dan kontrol manajemen. Metode penelitian menggunakan asosiasif kausal, dengan jumlah responden sebanyak 120 orang. Teknik analisis menggunakan pendekatan statistik regresi linear. Hasil penelitian mengemukakan, budaya kerja dapat menjelaskan motivasi kerja dengan estimasi regresi sebesar 0,701 dan kontrol manajemen memiliki peran sebesar 0,718 . Temuan ini secara komparasi menyatakan, bahwa pegawai memiliki kecenderungan sangat semangat jika perusahaan menerapkan fungsi kontrol yang baik. Hal ini dapat terjadi karena pengendalian mempengaruhi perasaan tidak enak pegawai dalam bekerja, sehingga peluang malas dan atau kurang bertanggung jawab menjadi berkurang. Selain itu, dilakukannya kontrol manajemen melahirkan anggapan atau pegawai merasa diperhatikan, sehingga bersemangat menjalankan tugas.
\end{abstract}

Kata Kunci: Budaya Kerja, Kontrol Manajemen, Motivasi Kerja

\section{ABSTRACT}

Work motivation is a psychological factor for performance, achievement, and work productivity. That is, morale is a variable that determines the quality of work implementation, the extent to which employees have a high desire and a feeling of optimism in achieving the goals that have been set. This study aims to reveal the possibility of work motivation in terms of culture and management control aspects. The research method uses causal association, with a total of 120 respondents. The analysis technique uses a linear regression statistical approach. The results showed that work culture can explain work motivation with a regression estimate of 0.701 and management control has a role of 0.718 . This finding, in comparison, states that employees have a tendency to be very enthusiastic if the company implements a good control function. This can happen because control affects employees' feelings of discomfort at work, so that the opportunities for laziness and or lack of responsibility are reduced. In addition, the implementation of management control gives birth to the assumption that employees feel cared for, so they are enthusiastic about carrying out their duties.

Keywords: Work Culture, Management Control, Work Motivation

\section{PENDAHULUAN}

PT. Bank Rakyat Indonesia Tbk Cabang Jakarta Kramat yang merupakan kantor cabang, yang memiliki BRI Cabang Jakarta Kramat memiliki kantor cabang pembantu ada 3 yaitu KCP Manggarai, KCP Pramuka, dan KCP BPKP. Juga memiliki 5 Kantor Kas terdiri dari: Kantor Kas KEMSOS, Kantor Kas KEMHAN, Kantor Kas RSCM, Kantor Kas KENARI MAS, dan Kantor Kas CAROLUS menerapkan nilai-nilai perusahaan (corporate value) menjadi landasan berpikir, bertindak serta berperilaku.

Proses penerapan budaya kerja di PT. Bank Rakyat Indonesia Tbk dikenal sebagai TRAMPIL (Alim, Baik, Terpercaya, Berkualitas, Ahli, Integritas, Berwawasan) 
dan kemudian digantikan oleh IKI (Integritas, Teladan dan Identitas). Banyak faktor yang dapat mempengaruhi peningkatan produktivitas tenaga kerja, antara lain: Contoh: budaya kerja, lingkungan kerja, manajemen usaha dan kemauan bekerja [1]. Hal ini juga dapat menyebabkan rendahnya produktivitas tenaga kerja. Oleh karena itu, perusahaan perlu memastikan bahwa sistem budaya kerja, lingkungan kerja, manajemen bisnis, dan kemauan bekerja mereka memenuhi kriteria "wajar" dan "cukup". Demikian pula, sistem yang menghargai kinerja pekerja juga dapat meningkatkan produktivitas pekerja [2]. Jika perusahaan mengevaluasi kinerjanya, semua karyawan bekerja keras, dan jika diasumsikan bahwa karyawan bekerja dengan tekun dan sumber daya dari semua perusahaan lain mendukungnya, mereka menunjukkan produktivitas tenaga kerja yang tinggi [3]. Budaya tempat kerja dipraktekkan di

PT. Bank Rakyat Indonesia Tbk Cabang Kramat Jakarta yaitu kejujuran (melakukan apa yang dikatakan, disiplin dan amanah), kolaboratif (empatik, partisipatif, memberdayakan), antusias (energik, terbuka dan positif) Kompetensi (pengembangan diri terus menerus, penguasaan domain, kreativitas) keandalan) dan fokus pelanggan (pelayanan prima, kemampuan beradaptasi, solusi) sangat kompleks dalam semua aspek yang ada. Inilah salah satu manfaat dari budaya perusahaan PT. Bank Rakyat Indonesia Tbk Cabang Kramat Jakarta berfokus pada kepentingan organisasi, tidak semua organisasi memiliki semua nilai yang dibutuhkan karyawannya, dibandingkan dengan organisasi dan bisnis lain. Melihat fenomena saat ini, budaya organisasi diharapkan dapat memberikan dampak positif terhadap produktivitas karyawan [4]. pt. Bank Rakyat Indonesia Tbk telah bekerja sama dengan PT sejak tahun 1998 membentuk Tim Budaya Kerja (TBKBRI) melalui transformasi budaya dari birokrasi ke bisnis. Service Quality Center Indonesia menggali dan mengembangkan budaya perusahaan BRI berdasarkan lima nilai budaya inti: inklusif, profesionalisme, kepuasan nasabah, modelability dan menghormati sumber daya manusia (SDM).

Sejalan dengan penjelasan di atas, berdasarkan data kehadiran pegawai diperoleh informasi/ keterangan bahwa pada tahun 2017 sampai dengan tahun 2020, menunjukkan bahwa absensi karyawa secara keseluruhan dalam kondisi yang kurang baik, dimana jumlah dari keseluruhan karyawan yang tidak masuk kerja karena sakit, izin, cuti maupun alfa menunjukkan trend yang meningkat, hal ini mengindikasikan masih rendahnya budaya kerja karyawan, sehingga perlu adanya penerapan sanksi dan kontrol terhadap kinerja kerja karyawan [5].

Menurut salah satu responden menyampaikan bahwa, PT. Bank Rakyat Indonesia Tbk Cabang Jakarta Kramat masih kurang dalam memberikan dukungan organisasi kepada karyawan yang berprestasi kerja. Upaya memberikan motivasi kerja oleh perusahaan kepada karyawan, namun terdapat karyawan yang belum memiliki semangat dan gairah dalam bekerja khususnya di bidang keuangan, juga masih terdapat karyawan yang masih nyaman di zona amannya, sehingga kurang meningkatkan potensi diri. Keadaan tersebut berdampak terhadap pencapaian target dan realisasi.

Berdasarkand data pada tahun 2017 sampai dengan tahun 2020, Pada Tahun 2019 terjadi penurunan yang siknifikan dengan hasil paling terendah dengan nilai $79 \%$, yang disebabkan oleh masih rendahnya semangat dan budaya kerja karyawan sehingga pencapaian laba perusahaan tidak mencapai target yang ditentukan.

Masalah di atas mengisyaratkan perlunya fungsi pengendalian, artinya manajemen perusahan harus mengoptimalkan aktivitas pengawasan, evaluasi, penilaian dan timbal balik [6]. Hal tersebut dapat memicu kesadaran diri pegawai untuk bekerja dengan penuh tanggung jawab dan berorientasi pada hasil yang maksimal [7]. 


\section{LANDASAN TEORI Budaya Kerja}

Koentraningrat "kebudayaan adalah keseluruhan manusia dari kelakuan dan hasil kelakukan yang teratur oleh tatakelakuan yang harus didapatnya dengan belajar dan semuanya tersusun dalam kehidupan masyarakat" [8]. Menurut Edgar H. Schein "mendefinisikan budaya sebagai suatu pola asumsi dasar bersama yang dipelajari kelompok tertentu untuk mengatasi masalah adaptasi eksternal dan integrasi internal yang resmi dan telah bekerja dengan baik dan oleh karena itu diajarkan/diwariskan kepada anggota - anggota baru sebagai cara yang tepat memahami, memikirkan dan merasakan terkait dengan masalah- masalah tersebut" [9].

Sedangkan menurut Robbin "budaya merupakan suatu sistem makna bersama yang dianut oleh anggota-anggota organisasi- organisasi lain" [10]. Adam Ibrahim "budaya organisasi merupakan keseluruhan nilai, norma-norma, kepercayaankepercayaan dan opini-opini yang dianut dan dijunjung tinggi bersama oleh para anggota organisasi, sehingga kebudayaan tersebut memberikan corak kepada anggota organisasi, kebiadaan dan tradisi" [11].

\section{Kontrol Manajemen}

Menurut George R. Terry "Kontrol dapat dirumuskan sebagai proses penentuan apa yang harus dicapai yaitu standard, apa yang sedang dilakukan yaitu pelaksanaan, menilai pelaksanaan, dan bila mana perlu melakukan perbaikan -perbaikan, sehingga pelaksanaan sesuai dengan rencana, yaitu selaras dengan standard (ukuran)" [12]. Kontrol mempunyai perananan atau kedudukan yang penting sekali dalam manajemen, mengingat mempunyai fungsi untuk menguji apakah pelaksanaan kerja teratur tertib, terarah atau tidak.

Menurut Moekizat "kontrol adalah hal yang dilakukan, artinya hasil pekerjaan, menilai hasil pekerjaan tersebut, dan apabila perlu mengadakan tindakan-tindakan perbaikan sehingga hasil pekerjaan sesuai dengan rencana" [13]. Dengan kata lain, kontrol manajemen merupakan salah satu pekerjaan yang dilaksanakan dalam kegiatan manajerial untuk menjamin terealisasinya semua rencana yang telah ditetapkan sebelumnya serta pengambilan tindakan perbaikan bila diperlukan.

\section{Motivasi Kerja}

Winardi mengemukakan bahwa "motivasi merupakan suatu kekuatan potensial yang ada di dalam diri seorang manusia, yang dapat dikembangkannya sendiri atau dikembangkan oleh sejumlah kekuatan luar yang pada intinya berkisar sekitar imbalan moneter dan imbalan non moneter, yang dapat mempengaruhi hasil kinerjanya secara positif atau negatif" [14]. Sedangkan Malayu pengertian "motivasi adalah mempersoalkan bagaimana cara mendorong gairah kerja bawahan, agar mereka mau bekerja keras dengan memberikan semua kemampuan dan keterampilan untuk mewujudkan tujuan perusahaan" [15]. Berdasarkan dua penjelasan tersebut, maka dapat disintesiskan bahwa motivasi merupakan dorongan diri dan atau dorongan luar yang membangkitkan semangat di dalam bekerja.

\section{METODOLOGI PENELITIAN}

Penelitian ini dilakukan pada PT. Bank Rakyat Indonesia Tbk Cabang Jakarta Kramat, yang berlokasi di Jalan Kramat Raya No.138, Jakarta Pusat 10430, Telepon: 310015255, Fax: 3100156. Adapun penelitian ini dilakukan secara bertahap disesuaikan dengan tingkat kebutuhan penulis. Tahap awal adalah mengeksplorasi permasalahan yang terjadi, dilanjutkan persiapan penulisan proposal penelitian. Tahap selanjutnya penulis menentukan responden dan narasumber dengan membuat daftar pertanyaan untuk memperoleh data untuk dilakukan analisis lebih lanjut. Kemudian 
tahap terakhir adalah penyusunan laporan hasil penelitian selain itu dilakukan pula pemeriksaan kembali apakah data yang perlu ditambahkan dalam hasil penelitian.

Dalam survei ini, populasinya meliputi seluruh karyawan PT. Bank Rakyat Indonesia Tbk Cabang Kramat Jakarta memiliki total 172 karyawan di beberapa departemen/departemen. Dalam penelitian ini, seluruh karyawan PT dilakukan sampling dengan menggunakan probabilistic sampling. Bank Rakyat Indonesia Tbk Cabang Kramat Jakarta memiliki kesempatan yang sama untuk dipilih menjadi anggota sampel. Metode yang digunakan untuk menentukan ukuran sampel dalam penelitian ini menggunakan rumus Slobin. Dari hasil perhitungan didapatkan sampel yang banyak hingga 120 orang.

\section{HASIL PENELITIAN DAN PEMBAHASAN \\ Tinjauan Kuesioner Budaya Kerja}

Para pegawai menganggap baik budaya kerja di PT. Bank Rakyat Indonesia Tbk Cabang Jakarta Kramat dengan skor 3,70. Hal ini menjelaskan bahwa secara umum nilai-nilai budaya kerja di PT. Bank Rakyat Indonesia Tbk Cabang Jakarta Kramat memiliki muatan yang baik, sehingga dapat dilaksanakan dalam setiap aktivitasnya. Kemudian indikator yang paling baik adalah integritas, artinya para pegawai benarbenar mengamalkan nilai-nilai budaya yang berbasis pada nilai-nilai, etika dan norma. Namun demikian indikaotr keteladanan dinilai paling rendah, hal ini mengisyaratkan bahwa pelaksanaan nilai-nilai budaya belum menjadi sebuah karakter.

\section{Tinjauan Kuesioner Kontrol Manajemen}

Secara total, 120 responden menyatakan bahwa kontrol manajemen di PT. Bank Rakyat Indonesia Tbk Cabang Jakarta Kramat sudah baik, dengan skor 3,60. Namun jika kita bandingkan dengan variabel budaya, maka terlihat ada penurunan persepsi pada variabel kontrol. Hal ini sejalan dengan tanggapan responden terhadap indikator tindakan manajemen, yang dinilai kurang baik. Dengan kata lain, manajemen PT. Bank Rakyat Indonesia Tbk Cabang Jakarta Kramat belum maksimal dalam menjalankan fungsi-fungsi manajemen, khususnya terkait dengan pengendalian yang bersifat operasional, yakni suatu tindakan pengawasan yang berbasis pada pendekatan realisasi di lapangan, termasuk kendala dan masalah yang dihadapi.

\section{Tinjauan Kuesioner Motivasi Kerja}

Motivasi kerja pegawai dinilai baik dengan skor 3,80. Hal ini menejaskan bahwa semangat kerja pegawai dalam keadaan baik, walau dalam beberapa hal dan kondisi perlu ditingkatkan. Namun secara komparatif, persepsi terhadap motivasi kerja menunjukkan angka yang sangat besar. Tentu, hal tersebut memiliki makna bahwa dalam hal motivasi kerja, pegawai cukup menjaga dan memelihara. Sehingga dalam setiap melaksanakan tugas motivasi kerja selalu dihadirkan. Namun demikian, motivasi kerja perlu diperbaiki dalam konteks fisiologis. Para pegawai menilai, PT. Bank Rakyat Indonesia Tbk Cabang Jakarta Kramat belum maksimal dalam memberikan stimulus yang bersifat fundamental.

\section{Pengaruh Budaya Kerja Terhadap Motivasi Kerja}

Nilai regresi sebesar 0,701 dengan tren positif. Artinya, budaya kerja dapat mengjelaskan bagaimana motivasi dapat meningkat secara matematis. Dalam arti luas, temuan ini menjelaskan bahwa aturan dan ketentuan dalam bekerja yang memiliki unsur nilai-nilai, kemudian menjadi sebuah cara di dalam menjalankan tugas, secara kuantitatif dapat mempengaruhi perasaan seseorang dalam bekerja, misalnya senang dan optimis. Bahkan menariknya lagi, jika budaya telah menjadi kebiasaan banyak orang, maka budaya akan berubah menjadi sebuah stimulus yang paling besar dalam mendorong orang untuk selalu melakukan yang terbaik, atau merasa perlu menjadi yang terbaik. Dalam banyak literatur, semangat kerja sangat ditentukan oleh 
seberapa dalam nilai-nilai kerja menjadi bagian dari karakter, sikap dan perilaku. Karena pada dasarnya setiap orang merasa butuh dengan nilai-nilai kebaikan itu sendiri.

\section{Pengaruh Kontrol Manajemen Terhadap Motivasi Kerja}

Pengendalian manajemen (X2) berpengaruh positif dan signifikan terhadap motivasi kerja (Y). Hal ini dapat dibuktikan dengan nilai koefisien regresi $(b) 0,718$ (positif). Ini menunjukkan efek satu arah. Dengan kata lain, setiap pengendalian manajemen (X2) meningkat sebesar 1 unit, dan motif kerja operasi (Y) meningkat sebesar 0,718 unit. Nilai regresi beta adalah $0,086 \mathrm{X} 2$. Artinya jika variabel manajemen usaha (X2) meningkat 1 unit, maka perilaku motivasi kerja (Y) meningkat sebesar 0,086 unit, dengan asumsi variabel budaya kerja (X1) dipertahankan.

Nilai koefisien determinasi sebesar 0,547 . Artinya, pengendalian manajemen (X2) memberikan kontribusi $54,7 \%$ terhadap variabel motivasi kerja $(Y)$ dan sisanya sebesar $45,3 \%$ dipengaruhi oleh variabel lain yang tidak dipertimbangkan dalam penelitian ini. Jika nilai thitung kontrol kontrol adalah 7,723 > ttabel 1,971, signifikansi 0,000 \& It;0,05, maka $\mathrm{HO}$ ditolak dan $\mathrm{Ha}$ diterima. Hal ini menunjukkan bahwa pengendalian manajemen berpengaruh positif dan signifikan terhadap motivasi kerja.

\section{Pengaruh Budaya Kerja dan Kontrol Manajemen Terhadap Motivasi Kerja}

Budaya kerja (X1) dan pengendalian manajemen (X2) secara bersamaan berpengaruh positif dan signifikan terhadap motivasi kerja $(\mathrm{Y})$. Hal ini dapat dijelaskan dengan nilai Fhitung 84,898 > Ftabel 2,68 (signifikansi 0,000 \& It;). Karena 0,05 maka Ho ditolak dan Ha diterima. Artinya budaya kerja (X1) dan pengendalian manajemen (X2) berpengaruh positif dan signifikan terhadap motivasi kerja (Y) secara bersamaan. PT Bankrayat Indonesia Tbk Cabang Kramat Jakarta. Nilai

R-kuadrat adalah 0,592 . Artinya budaya kerja (X1) dan manajemen usaha (X2) memberikan kontribusi terhadap motivasi kerja $(Y)$ yang berfluktuasi sebesar $59,2 \%$, dan sisanya 40,8\% dipengaruhi oleh variabel lain. Hasil ini mempertegas, agar motivasi kerja pegawai meningkat maka diperlukan suatu upaya penguatan budaya dan peran manajemen. Tentu hal tersebut berada pada kendali pimpinan, dengan demikian perusahaan harus memiliki sistem kepemimpinan yang baik sebagai pendukung dari optimalisasi penerapan budaya dan kontrol manajemen.

\section{KESIMPULAN DAN SARAN}

Hasil penelitian menunjukkan bahwa budaya kerja dan kontrol manajemen memiliki hubungan yang linear dengan motivasi kerja. Hal ini menegaskan, bahwa keberadaan budaya kerja memiliki peran positif dalam meningkatkan semangat kerja, sehingga memiliki implikasi perlunya melakukan penguatan nilai-nilai kerja yang berasaskan pada etika dan norma. Selain itu, Kontrol manajemen juga perlu dilakukan, agar tercipta suasana kerja formal. Artinya, adanya pengawasan membuat para pegawai merasa diawasi, sehingga perasaan semangat berkaja akan terpelihara.

Selain itu, penelitian ini menegaskan bahwa peran manajemen dominan terhadap semangat kerja. Hal ini mengisyaratkan perlunya penguatan fungsi pengawasan, penilaian, peninjauan, pelaporan, dan evaluasai. Tentu, dengan optimalnya fungsi kontrol manajemen dapat membantu mengarahkan dan memandu pegawai untuk senantiasa mengerjakan tugas sesuai kententuan yang berlaku.

\section{DAFTAR PUSTAKA}

[1] Fauzi, I. (2021). Efek Mediasi Motivasi Kerja Pada Pengaruh Budaya Organisasi Terhadap Kinerja. Maneggio: Jurnal IImiah Magister Manajemen, 4(2). 
[2] Sukmayanti, E., Hidayat, N., \& Herfina, H. (2021). PENGUATAN KEPEMIMPINAN VISIONER DAN MOTIVASI KERJA DALAM UPAYA MENINGKATKAN KREATIVITAS GURU. JURNAL MANAJEMEN PENDIDIKAN, 9(2), 96-101.

[3] Situmeang, L. (2021). Analisis Hubungan Kepemimpinan Dan Budaya Organisasi Dengan Motivasi Kerja Dalam Penerapan Good Governance. Jurnal Manajemen Strategi dan Aplikasi Bisnis, 4(1), 305-314.

[4] Hutajulu, Y. M. M., Sintani, L., \& Meitiana, M. (2021). Pengaruh disiplin dan budaya kerja terhadap kinerja ASN melalui motivasi kerja Satpol PP Provinsi Kalimantan Tengah. Journal of Environment and Management, 2(1), 44-52.

[5] Upa, M. P., Idris, M., \& Maryadi, M. (2021). Pengaruh Budaya Organisasi, Disiplin dan Motivasi Kerja Terhadap Kinerja Pegawai SMK Negeri di Kabupaten Manokwari. Journal of Applied Management and Business Research (JAMBiR), $1(2), 133-142$.

[6] Herianto, S. (2021). PENGARUH MOTIVASI KERJA, BUDAYA ORGANISASI DAN LINGKUNGAN KERJA TERHADAP KEPUASAN KERJA IMPLEMENTASINYA PADA KINERJA PEGAWAI UPTD WILAYAH III DPKA (SAMSAT) KABUPATEN BIREUEN. JURNAL KEBANGSAAN, 10(19), 1-11.

[7] Widodo, S., Hidayat, A. C., \& Sutanto, A. (2021). PENGARUH BUDAYA KERJA, KEMAMPUAN KERJA, DAN KOMITMEN ORGANISASI TERHADAP KINERJA PEGAWAI MENJELANG MASA PURNABAKTI PADA LINGKUP KANWIL DITJEN PERBENDAHARAAN PROVINSI DI YOGYAKARTA. Value: Jurnal Manajemen dan Akuntansi, 16(1), 188-197.

[8] Nuriyah, S., \& Azizah, N. (2021). PENGARUH KEPEMIMPINAN, MOTIVASI KERJA DAN BUDAYA ORGANISASI TERHADAP LOYALITAS KARYAWAN. Jurnal Analitika Bisnis, Ekonomi, Sosial dan Politik, 1(01), 22-31.

[9] Pratiwi, N. M. D. D., \& Bagia, I. W. (2021). Motivasi Kerja Dan Kemampuan Kerja Mempengaruhi Kinerja Pegawai Pada Pdam Tirta Amertha Jati Kabupaten Jembrana. Prospek: Jurnal Manajemen dan Bisnis, 3(1), 21-28.

[10] Djaman, S., Hasanuddin, B., \& Rudin, R. (2021). Pengaruh Motivasi Kerja, Disiplin Kerja dan Budaya Organisasi terhadap Kinerja Pegawai Kesehatan Rumah Sakit Umum Daerah Tora Belo Kabupaten Sigi. JAMIN: Jurnal Aplikasi Manajemen dan Inovasi Bisnis, 3(2), 25-37.

[11] Jayanti, G. A., \& Nazwirman, N. (2020). Model Kinerja Pegawai: Kepemimpinan, Budaya Kerja, dan Motivasi Kerja dengan Kepuasan kerja variabel intervening. Jurnal IImiah Manajemen dan Bisnis, 21(2), 157-173.

[12] Jayanti, G. A., \& Nazwirman, N. (2020). Model Kinerja Pegawai: Kepemimpinan, Budaya Kerja, dan Motivasi Kerja dengan Kepuasan kerja variabel intervening. Jurnal IImiah Manajemen dan Bisnis, 21(2), 157-173.

[13] Fachrezi, H., \& Khair, H. (2020). Pengaruh Komunikasi, Motivasi dan Lingkungan Kerja Terhadap Kinerja Karyawan Pada PT. Angkasa Pura II (Persero) Kantor Cabang Kualanamu. Maneggio: Jurnal Ilmiah Magister Manajemen, 3(1), 107-119.

[14] Violin, V. (2020). PENGARUH KOMPETENSI, PENGALAMAN DAN BUDAYA KERJA TERHADAP KINERJA KARYAWAN DINAS TOWER DAN GROUND CONTROL MAKASSAR AIR TRAFFIC SERVICE CENTER (MATSC). Jurnal Mirai Management, 5(2), 481-489.

[15] Novitasari, Y., \& Rivai, H. A. (2020). Pengaruh Budaya Organisasi, Komitmen Organisasional dan Motivasi Kerja Terhadap Kinerja Karyawan pada PT. XXX. Jurnal Mirai Management, 5(2), 332-353. 